H.G.L. Peels

Theological University Appeldoorn, The Netherlands, Research fellow: Department Old and New

Testament Studies, University of the Free State, South Africa.

E-mail:

hglpeels@tua.nl

DOI: http://dx.doi. org/10.18820/23099089/ actat.Sup26.8

ISSN 1015-8758 (Print)

ISSN 2309-9089 (Online)

Acta Theologica 2018

Suppl 26:136-154

(C) Creative Commons

With Attribution (CC-BY)
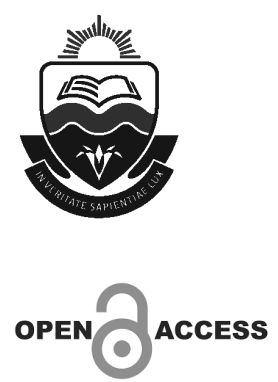

\section{DE VOLGORDE VAN DE VOLKENPROFETIEËN IN HET BOEK JEREMIA}

\author{
ABSTRACT
THE ORDER OF THE ORACLES AGAINST THE NATIONS IN THE BOOK OF JEREMIAH

The textual tradition of the Book of Jeremiah shows two different orders of the collection of the Oracles Against the Nations (OAN). Recently, an increasing majority of scholars have given preference to the sequence of the OAN collection in JerLXX as being the more original one. It remains uncertain, however, whether this growing consensus is, in fact, valid. In this article, I develop four arguments that question the preference for the Greek order of the OAN collection in Jeremiah. Alternatively, I present a hypothesis for the originality of the MT order and a possible reason for its reworking at a later period.

\section{INLEIDING}

Het is een genoegen een bijdrage te leveren aan het Festschrift voormijn emeriterende collegaprof. Fanie Snyman, met respect voor zijn wetenschappelijke bekwaamheid en met dankbaarheid voor zijn warme vriendschappelijkheid. Waar wij elkaar al vroeg in vonden, was de passie voor de oudtestamentische profetie. Prof. Snyman (2015) schreef, voor Historical Commentary on the Old Testament, een belangwekkende commentaar op het boek Maleachi. Ik bereid in deze reeks een deel over het boek Jeremia voor. Wij bewaren een mooie herinnering aan de bundel The lion has roared. Theological themes in the prophetic literature of the Old Testament, die wij in 2012 samen redigeerden. Als een hommage aan het adres van de terugtredende oudtestamenticus uit Bloemfontein bied ik hem deze kleine vrucht uit mijn profetenonderzoek aan. 


\section{VRAAGTEKENS BIJ EEN GROEIENDE CONSENSUS}

Van het boek Jeremia bezitten wij twee versies: de kortere Griekse tekst (JerLXX) en de langere Hebreeuwse tekst (JerMT). De relatie tussen deze beide is bijna twee eeuwen lang voorwerp van intensief debat. De oudere mening dat de kortere tekst een secundaire ontwikkeling vormt ten opzichte van de langere tekst is door nader onderzoek naar de aard van zowel de Griekse vertaling als de Hebreeuwse tekst, en met name na de vondst van twee Qumran-manuscripten (4Q71=4QJer en $\left.4 Q 72 a=4 Q J e r^{d}\right)$ die dichter bij JerLXX dan bij JerMT staan, inmiddels tamelijk breed verlaten. In de afgelopen decennia tekent zich een consensus af dat JerLXX teruggaat op een Hebreeuwse Vorlage die een eerder stadium in de literaire ontwikkeling van het boek weerspiegelt dan die van JerMT (Carroll 1986:51). Wel betreft het een relatieve prioriteit, omdat JerLXX zelf op kleinere onderdelen ook weer een latere ontwikkeling vertoont ten opzichte van JerMT (Stipp 1994). Slechts een kleine minderheid van geleerden blijft pleiten voor de prioriteit van JerMT. ${ }^{1}$

Een belangrijk onderdeel van deze discussie betreft de positie en volgorde van de bundel volkenprofetieën (OAN = Oracles Against the Nations) in het boek Jeremia. Zoals bekend, staat deze bundel bij JerLXX in het midden (25:14-31:44) en bij JerMT aan het einde van het Boek (46:1-51:64). Overheersend is de overtuiging dat de positie van de bundel in JerLXX de oorspronkelijke was en dat op dit punt JerMT een secundaire bewerking vertoont. Een belangrijk argument hierbij vormt de verankering van de bundel in de context van Jeremia 25, waarvan 25:1-13(14) de inleiding op de volkenprofetieën lijkt te zijn, met de bekerperikoop 25:15-38 als afsluiting (Aejmelaeus 2002:479; zie echter Rofé 1989:397).

Over de volgorde van de profetieën binnen de bundel gaan de gedachten meer uiteen. Wie reeds van mening was dat de plaats van de OAN-bundel in JerMT prioriteit toekomt, gaat evenzo uit van de originaliteit van de volgorde in JerMT (Fischer 1991:498; Haran 2003:700; Rofé 1989:392; Schmidt 2013:279, 281). Maar ook diverse exegeten die opteren voor de prioriteit van de plaats van de OAN-bundel in JerLXX, beschouwen toch de volgorde van de volkenprofetieën in JerMT als de meer oorspronkelijke (Rudolph 1968:265; Fohrer 1981:46; Lundbom 2004:181; Volz 1928:382; Holladay 1986:5; Holladay 1989:313; Weiser 1977:381; McKane 1996:111). De argumentatie hiervoor is doorgaans echter beperkt, algemeen acht men

1 Bijvoorbeeld, G. Fischer, A. Rofé, J.R. Lundbom, Chr.R. Seitz, en M. Haran. Zie het beknopte overzicht van de Forschungsgeschichte bij Backhaus \& Meyer (2012:549-551); Gesundheit (2012:29-36); Weiss (2017:499-504); Lange (2017:519-520). 
dan de volgorde in JerMT zakelijk juister en ook logischer. Het is juist om deze reden dat anderen in de volgorde van JerMT het resultaat van latere uniformering en theologische redactie zien. In het recente onderzoek lijkt op dit punt nu een consensus te groeien, namelijk dat niet alleen de plaats maar ook de volgorde van de OAN in JerLXX oorspronkelijk is.

Het is bij deze groeiende consensus ten aanzien van de volgorde van de volkenprofetieën dat ik graag enkele kanttekeningen wil plaatsen. De complexiteit van de redactie- en tekstgeschiedenis van het Boek Jeremia is dermate groot, dat mijn bijdrage zich moet beperken tot een aantal observaties, die een nadere discussie zouden kunnen dienen. Eerst geef ik een samenvatting van de ideeën over de ratio achter de OAN-volgorde (§ 2). Daarna bespreek ik de argumenten die in de genoemde consensus een rol spelen (§ 3). Mijn "kanttekeningen", vier in totaal, komen aan bod in §§ 4-7. De eerste twee daarvan zijn iets breder van aard, het gewicht van de argumentatie pro de volgorde in JerMT ligt vooral bij de laatste twee kanttekeningen. Het geheel wordt afgesloten met een conclusie en een hypothese, waarbij ik vooral focus op de mogelijke betekenis van de prioritering van de Elam-profetie in JerLXX (§ 8).

Tabel 1: Volgorde van OAN

\begin{tabular}{|l|l|l|}
\hline \multicolumn{1}{|c|}{ JerLXX } & \multicolumn{1}{|c|}{ JerMT } & Bekervisioen (25:15-38) \\
\hline \multirow{2}{*}{ Elam (25:14-19) } & Egypte (46) & (Jeruzalem/Juda) \\
Egypte (26) & Filistea (47) & Egypte/Uz \\
Babel (27-28) & Moab (48) & Filistea \\
Filistea (29:1-6) & Ammon (49:1-6) & Edom \\
Edom (29:8-23) & Edom (49:7-22) & Moab \\
Ammon (30:1-5) & Damascus (49:23-27) & Ammon \\
Kedar/Hazor & Kedar/Hazor & Fenicië \\
(30:6-11) & (49:28-33) & Arabië \\
Damascus & Elam (49:34-39) & Elam/Medië (Perzië) \\
(30:12-16) & Babel (50-51) & (Babel) \\
Moab (31) & & \\
\hline
\end{tabular}




\section{DE ZIN VAN DE VOLGORDE VAN DE OAN}

De vraag naar de ratio achter de volgordes van de volkenprofetieën in JerMT en in JerLXX heeft verschillende antwoorden gekregen. Wat JerMT betreft, denkt men zowel aan een chronologische als aan een geografische ordening (Peels 2007:82-83). Allen (2008:458-460) heeft een afwijkende visie op de volgorde van de OAN in JerMT, waarbij zijns inziens Ammon centraal staat. De eerste optie is mede afhankelijk van de datering van elk van de profetieën, waarvoor echter de nodige gegevens ontbreken. De bundel zelf presenteert zich als een verzameling profetieën die uitgesproken zijn tussen het vierde jaar van Jojakim (Jer. 46:2) en het vierde jaar van Zedekia (Jer. 51:59), dus tussen 605 en 594 BCE, de periode van de expansie van het Nieuw-Babylonische wereldrijk. Volgens de tweede optie toont de bundel een beweging van het zuiden naar het westen en vervolgens van het oosten naar het noorden (Pfeiffer 1948:509; Fohrer 1981; deels Holladay 1989:313; zie ook Kessler 2003:167-168). Deze lijn kan maar moeilijk overtuigen.

Literair-theologisch heeft de OAN-bundel in JerMT echter een zinvolle opbouw. Onmiskenbaar is de betekenis van de positionering van Egypte op de eerste en van Babel op de laatste plaats in de bundel. Het betreft de twee grote antagonisten die de wereld van Jeremia's dagen beheersen (Rofé 1989:392; Kessler 2003:166). JerMT lijkt met deze volgorde heen te werken naar de apotheose van het hele boek: Babel aan het slot, als culminatie van Gods gericht over alle volken - met een boodschap van oordeel en hoop.

Moeilijker is het om in de volgorde van de bundel in JerLXX een bijzondere reden te ontdekken. Heeft JerLXX een meer formeel-zakelijke indeling, met vooropstelling van de drie grote rijken Elam (= Perzië, zie onder), Egypte en Babel, en daarna de reeks kleinere volken (Rudolph 1968:266; Weiser 1977:381; Fischer 1991:494)? Geven de grote rijken eerst de grenzen van Gods gericht aan, waarbinnen dan de overige volken op hun beurt het oordeel ondergaan (Woods 2011:45)? De vraag is dan wel waarom niet Babel of Egypte de reeks opent. Even speculatief is de gedachte dat Moab de bundel in JerLXX afsluit vanwege de notie "dronkenschap" (31:26), die een goede aansluiting met de bekerperikoop in hoofdstuk 32 JerLXX zou geven. ${ }^{2}$ Hoe het ook zij, de functie van Babel is in de OAN-bundel van JerLXX beduidend anders dan die in JerMT.

Al met al kan gesteld worden dat de volgorde in JerMT historisch, literair en theologisch een duidelijker beeld biedt dan die in JerLXX: "No

2 Zie de discussie bij Woods (2011:45-46). 
discernible order can be detected in G" (Carroll 1986:759). Beslissend voor de vraag naar de oorspronkelijkheid van de volgorde is dit echter nog niet. Een logischer volgorde kan op een oorspronkelijke samenstelling duiden, maar ook op een latere bewerking (Huwyler 1997:369). Nader onderzoek naar sporen van redactie binnen de OAN-bundel geeft evenmin uitsluitsel ten aanzien van de prioriteit van de ene of de andere volgorde. ${ }^{3}$ In toenemende mate zijn onderzoekers echter van mening dat wanneer de OAN bezien worden in het kader van de eindredactie van het hele Boek van Jeremia, de balans doorslaat naar de oorspronkelijkheid van de volgorde van de bundel zoals JerLXX die presenteert.

\section{PRIORITEIT VAN DE LXX-VOLGORDE?}

De zich aftekenende consensus ten faveure van de prioriteit van de OANvolgorde in JerLXX berust voornamelijk op drie lijnen van argumentatie.

Ten eerste wordt de overtuiging breed gedragen dat JerLXX een nauwgezette vertaling is die de Hebreeuwse brontekst zeer letterlijk heeft overgezet:

It is impossible to attribute to the translator any conscious changes in the text, not to speak of editorial activity. The translator of Jeremiah can be characterized as one of the most literal in the whole Septuagint (Aejmeleus 2002:461; Cook 1994:189; Finsterbusch \& Jacoby 2015:36; Weis 2017:496). ${ }^{4}$

Als de Griekse vertaler op deze wijze te werk ging, is het niet te verwachten dat hij een ingrijpende verandering aangebracht heeft in de volgorde van de bundel volkenprofetieën.

Ten tweede is te wijzen op de onmiskenbare relatie tussen de OANbundel en de bekerperikoop in 25:15-38 [32:1-24]. Beide kondigen het wereldwijde gericht aan en noemen daarbij grotendeels dezelfde naties, waarbij de MT-volgorde van de OAN overeenkomt met de volgorde van de volken in de bekerperikoop (zie Tabel 1). Het is plausibeler dat de OAN-structuur in JerMT een latere aanpassing is aan de volgorde in het bekervisioen (Chae 2015:588; Watts 1992:446), dan dat JerLXX de OANbundel bewust herstructureerde contrarie de volgorde in het bekervisioen dat deze bundel afsluit.

3 Zie de tegenstrijdige interpretaties van de OAN-redactie bij Watts (1992) en Huwyler (1997:370-381), enerzijds en Fischer (1991), anderzijds.

4 Fischer (2017:546-552) en Gesundheit (2012:30-36) hebben een andere mening hierover. 
Het derde en meest zwaarwegende argument is dat JerMT als geheel een meer gestroomlijnde structuur vertoont. Het volle accent wordt gelegd op Babel als voltrekker van Gods gericht (Gosse 1986:396; Carroll 1986:757), die ten slotte ook zelf onder het oordeel komt, waardoor er voor Juda weer toekomst gloort. Dit spoort met de explicitering en profilering van Babel en Nebukadnezar als Gods gerichtsinstrument door het boek heen, kenmerkend voor JerMT. De verplaatsing van de OAN-bundel naar het einde van het boek zorgt ook voor een logischer ordening: na en conform de oordeelsaankondiging in het bekervisioen (25:15-38) wordt in JerMT eerst het gericht over Juda beschreven (Jer. 26-45), daarna over de volken rondom (Jer. 46-49) en ten slotte over Babel (Jer. 50-51) (Stipp 2014; Chae 2015:588; Crouch 2017:68-69, 103-115). De herschikking van de OAN met Babel als laatste geeft aan het hele boek een meer positief slot: De grote vijand wordt geoordeeld, Juda wordt opgeroepen uit Babel weg te trekken. Als geheel lijkt JerMT dus een ten opzichte van JerLXX latere redactionele herstructurering te hebben gekregen, waarvan de volgorde van de OAN een functioneel onderdeel was (Watts 1992:432-447).

De volgorde van de OAN in JerLXX lijkt de lectio difficilior te zijn (zo reeds Janzen 1973; zie Chae 2015:587). Het ligt niet voor de hand dat een redactor van de LXX-Vorlage of de Griekse vertaler een oorspronkelijke structuur met een zo duidelijke en hoopvolle boodschap zou hebben omgebouwd tot een veel minder helder geheel. In dit licht gezien, is het begrijpelijk dat steeds meer geleerden opteren voor de originaliteit van de OAN-volgorde in JerLXX, en de volgorde in JerMT als het resultaat van een latere theologiserende redactie beschouwen. Toch blijven bij deze visie een aantal vragen open, die ik in mijn "kanttekeningen" wil verwoorden.

\section{KANTTEKENING (1): OP/ONDERSCHRIFTEN EN CHRONOLOGIE}

Een opvallend verschil tussen JerLXX en JerMT betreft het systeem van op- en onderschriften van de volkenprofetieën. Vergeleken met JerMT is JerLXX hierin veel beperkter. Zowel Fischer (1991:488-499) als Huwyler (1997:371-381) hebben deze systemen nader onderzocht, maar komen tot tegenovergestelde conclusies. Fischer is van mening dat de bundel OAN in JerMT een dubbel systeem van op-/onderschriften heeft: Jeremia 46-49 vormt een eigen blok met een eender opschrift voor de eerste twee volken (Egypte-Filistea), een eender onderschrift voor de twee daaropvolgende volken (Moab-Ammon) en bij de laatste profetie (Elam) zowel een dergelijk op- als onderschrift. Daarbij voegt zich een tweede structuur in de profetie tegen Babel (Jer. 50-51) die een opschrift heeft zoals 46:13 en een 
onderschrift zoals 48:47b. Dit dubbele systeem is signaal van successieve groei van de bundel. In JerLXX is dit dubbele systeem weggevallen en deels veranderd, wat derhalve op een secundaire ontwikkeling wijst, aldus Fischer - waarom zou immers in een latere ontwikkeling een uniform systeem vervangen zijn door een dubbel systeem (Fischer 1991:498). De analyse van de op- en onderschriften door Huwyler leidt tot een geheel andere slotsom. Hij is van mening dat dit systeem sporen van redactie vertoont, die met de verplaatsing van de bundel van het midden naar het slot van het boek en de herstructurering van de volgorde samenhangen. Met name 48:47b en 51:64 duiden zijns inziens op latere bearbeiding, en vormen aldus een aanwijzing voor de prioriteit van de volgorde in JerLXX.

Het blijkt niet goed te lukken om uit het verschillende systeem van op- en onderschriften eenduidige conclusies te trekken. Zo behoeft 48:47b niet per se geduid te worden als een afsluitende tekst voor de gehele oorspronkelijke OAN-bundel, maar kan dit vers eenvoudig gezien worden als passend slot van een opvallend lange volkenprofetie op zich (Finsterbusch \& Jacoby 2015:49-50). Evenzo kan 51:64 in een vroege fase de oorspronkelijke afsluiting van het Boek van Jeremia zijn geweest, die later in de LXX-Vorlage kwam te vervallen in verband met de positionering van de OAN-bundel in het midden van het boek. Hier blijft veel onzeker.

Toch lijkt JerLXX op het punt van op-/onderschriften sporen van secundaire bewerking ten opzichte van JerMT te vertonen, die kunnen samenhangen met een herordening van de volkenprofetieën. Ik noteer twee signalen daarvan, betreffende het opschrift van de Elam-profetie (49:34-39 [25:14-20]) en dat van de Filistea-profetie (47:1-7 [29:1-7]).

JerLXX heeft bij de opening van de OAN-bundel een hybride opschrift:

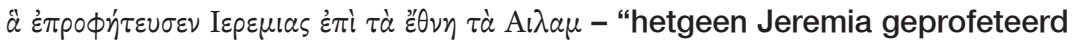
heeft over de volken van Elam" (25:14). ${ }^{5}$ De combinatie "de volken van Elam" is uniek, en wijkt af van alle andere opschriften. Het gaat om een combinatie van wat in JerMT 25:13b en 49:34 staat: "wat Jeremia over alle volken geprofeteerd heeft", respectievelijk "[wat als woord van JHWH tot de profeet Jeremia kwam] over Elam". JerLXX of reeds de Vorlage daarvan neemt vers $13 \mathrm{~b}$ als opschrift voor de hele OAN-bundel (vs. 14 mist in JerLXX), en verbindt deze tekst abusievelijk rechtstreeks met het opschrift van de Elam-profetie door "Elam" in appositie naast "de volken" te zetten. De historische notitie in het opschrift van de Elam-profetie in JerMT 49:34 heeft ook JerLXX, maar staat hier merkwaardig, want geheel a-typisch (historische notities staan in volkenprofetieën altijd in het opschrift) aan

$5 \quad$ Zie de discussie bij Fischer (1991:483 noot 28), Finsterbusch \& Jacoby (2015:41-42) en Huwyler (1997:374-376). 


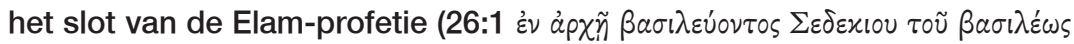

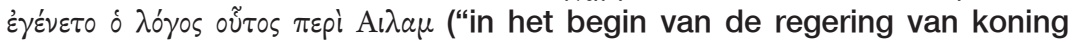
Zedekia kwam dit woord over Elam")). Deze observatie ten aanzien van op- en onderschrift van de Elam-profetie in JerLXX geeft aanleiding tot het vermoeden dat deze profetie oorspronkelijk op een andere plaats in de OAN-bundel stond, en dat de redactor bij het verplaatsen van de Elamprofetie de historische notitie als minder passend bij de opening van de bundel áchter de Elam-profetie heeft gezet.

Het opschrift van de Filistea-profetie heeft in JerMT de cryptische

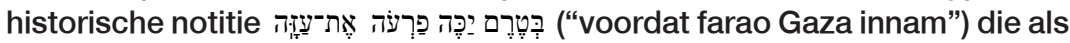
doelbewuste insert alleen verstaanbaar is in een zeer vroege fase van deze tekst, namelijk tegen de achtergrond van de gebeurtenissen rond $601 \mathrm{BCE}$ (Peels 2013). Het is mede door dit opschrift dat de Filistea-profetie nauw verbonden is met de Egypte-profetie. Het ontbreken van dit opschrift in JerLXX laat zich als secundaire weglating verklaren. Deze lapidaire notitie was voor de eerste hoorders/lezers van de profetie duidelijk, maar een raadsel voor de lezers in later eeuwen. Hierdoor was het des te gemakkelijker om de profetieën tegen Egypte en tegen Filistea los van elkaar in de OAN-bundel een plaats te geven.

Door de serie op- en onderschriften van de OAN-bundel in JerMT wordt een historische lijn zichtbaar, van 605 (de slag bij Karkemiš) tot 594 (het vierde jaar van koning Zedekia). Het jaar 605 markeert een keerpunt in de geschiedenis van het oude Nabije Oosten: de doorbraak van het NieuwBabylonische rijk onder Nebukadnezar. Alle op Jeremia 46:1 volgende profetieën staan in dit licht: de "hamer" Nebukadnezar legt zijn wil op aan de landen rondom. Dat de bundel uitloopt op de profetie over Babel zelf ligt geheel in de lijn van de narratieve en theologische dynamiek van het Boek van Jeremia. De OAN-bundel in JerLXX echter heeft een verspringende chronologie: 25:1, Jojakims vierde jaar; 25:20, Zedekia's eerste jaar; 26:1, Jojakims vierde jaar, en 28:50, Zedekia's vierde jaar.

Aan dit alles zijn nog geen dwingende conclusies ten aanzien van de prioriteit van de volgorde van JerMT of die van JerLXX te verbinden, maar deze gegevens dienen in een weging van argumenten wel verdisconteerd te worden.

\section{KANTTEKENING (2): DE PLAATS VAN DE PROFETIE TEGEN EGYPTE}

De OAN-bundel in JerMT opent met een (dubbele) profetie tegen Egypte (46:2-28) (Peels 2016). In JerLXX staat deze profetie echter op de tweede 
positie (26:2-28), na de profetie over Elam (25:14-26:1). Onmiskenbaar heeft in JerMT de profetie tegen Egypte veel meer dan in JerLXX een passende en functionele plaats, en wel in drie opzichten.

Ten eerste, in chronologisch opzicht, omdat deze profetie die in 605 BCE - of kort daarna - gedateerd kan worden (46:2), zeer vermoedelijk de oudste van de hele bundel is. De daaropvolgende profetieën bieden tezamen een beeld van de periode van Babels expansie na 605, en zullen uit later tijd dateren.

Ten tweede, in boek-structureel opzicht, omdat deze profetie direct aansluit bij de gebeurtenissen die in de direct voorgaande capita verhaald zijn: de ondergang van Juda en de wanhoopsvlucht naar Egypte (43:7), de profetie over de verovering van Egypte door Nebukadnezar (43:8-13) en de hernieuwde afgoderij van Juda in Egypte (44). Het oordeel door JHWH aangekondigd over al wat leeft (45:5), begint dichtbij: in het toevluchtsoord van de valse hoop, Egypte. Dit is ook de volgorde die wordt aangehouden in de bekerperikoop (25:15-29), waar beschreven wordt dat na Juda Egypte als eerste van de volken de beker zal moeten drinken.

In de derde plaats, in theologisch opzicht, omdat de profetische waarschuwing tegen vertrouwen op Egypte die door het hele Boek van Jeremia heen te vinden is, hiermee tot een climax komt: aan Egypte is geen enkele hoop meer te ontlenen. Het oordeel over Egypte is in het Boek van Jeremia overwegend negatief (zie Brueggemann 1998:24), en dit wordt door de positionering van de profetie tegen Egypte aan het begin van de bundel volkenprofetieën onderstreept.

\section{Das Gericht, mit dem JHWH seine unangefochtene Oberherrschaft über die Nationen demonstriert, „muss" bei Ägypten beginnen, weil die Judäer auf es ihre Hoffnungen gesetzt und es zu einer quasi-göttlichen theo-politischen Alternative gemacht haben (Maier 2002:277).}

Evenals bij de vorige kanttekening meen ik dat ook nu aan het bovenstaande nog geen dwingende conclusie ten aanzien van de prioriteit van de volgorde van JerMT dan wel JerLXX verbonden kan worden. Wel kan gezegd worden dat het ook voor de structurering van de OAN-bundel op de plaats waar deze in JerLXX is ingevoegd, voor de hand gelegen zou hebben met de profetie tegen Egypte te openen - maar dat dit blijkbaar bewust niet is gebeurd, omdat de voorkeur werd gegeven aan de Elamprofetie op deze positie. 


\section{KANTTEKENING (3): DE PLAATS VAN DE PROFETIE TEGEN ELAM}

De profetie tegen Elam (49:34-39), die in JerMT de overgang van de sectie 46-49 naar de grote Babel-profetie in 50-51 vormt, heeft de eerste positie in de OAN-bundel in JerLXX (25:14-26:1). Nu is Elam, in tegenstelling tot alle andere volken die in oudtestamentische volkenprofetieën figureren, voor Israël nooit van enig direct belang geweest, politiek noch economisch. Nergens elders staat in het Oude Testament een profetie tegen Elam. ${ }^{6}$ Wat is de zin van een oordeelsprofetie tegen een volk dat letterlijk en figuurlijk aan de uiterste rand van Israëls horizon leefde? In tegenstelling tot alle andere OAN in Jeremia is de profetie tegen Elam ook opmerkelijk "vaag": geografische en historische data ontbreken geheel. Ofschoon de naam Elam in elk vers van de profetie gebruikt wordt (in totaal zeven maal, op zich een opvallend gegeven), komt Elam zelf nergens nader in beeld.

In de Elam-profetie ligt alle accent op het goddelijk subject dat het oordeel aankondigt. Zonder parallel is de wijze waarop het goddelijk "Ik" letterlijk elk vers van deze profetie beheerst en in diverse verbindingen in totaal tien maal voorkomt. In de OAN-bundel van JerMT was niet eerder expliciet sprake van de goddelijke toorn als drijfveer achter het gericht over de volkeren, zoals in vers 37 geformuleerd wordt. Uniek is ook in vers 38 de metafoor van Gods troon die in Elam wordt opgericht, een zegswijze die de onweerstaanbare goddelijke soevereiniteit in het oordeel over Elam onderstreept. De enige parallel voor de uitdrukking is שים כסא is Jeremia 43:10, waar sprake is van Nebukadnezar die door JHWH ontboden wordt om zijn troon in Egypte op te richten. Hierin ligt mogelijk een verband tussen wat JHWH via Babel de volken aandoet en wat Hij zelf het nabij Elam gelegen Babel gaat aandoen.

Literair en inhoudelijk wijkt de profetie tegen Elam af van de voorgaande volkenprofetieën: onbepaald, vaag en compilatorisch. Onmiskenbaar vervult de profetie tegen Elam in de OAN-bundel van JerMT 46-51 een bijzondere functie. Enerzijds brengt de profetie tegen Elam (Jer. 46-49) tot een climax en een afsluiting. Gods oordeel wordt via Babel uitgevoerd: Egypte moet als eerste buigen, en vervolgens alle andere volken, in totaal zeven. Hierop volgt dan de anderssoortige profetie tegen Elam, die Jer. 46-49 in tweeërlei zin tot een climax brengt. Ten eerste, wordt door deze profetie de uitgestrektheid van het gericht over de volkeren geaccentueerd. Het verre Elam als een uitroepteken achter de volheid van zeven volken. De storm van het oordeel, waaraan niet één volk zal ontkomen, gaat van de Nijl tot gene zijde van de Eufraat en de Tigris. Ten tweede, wordt door de

Voor het volgende, zie Peels (2000:216-229). 
profetie tegen Elam de boodschap van de voorgaande capita ongemeen geïntensiveerd, doordat het wereldgericht dat ook Elam treft in elk vers van deze profetie door God zelf wordt uitgevoerd. De dreigende cadans van perfecta consecutiva in de eerste persoon enkelvoud accentueert de onontkoombaarheid en de ernst van het gericht. In het woeden van Babel toornt JHWH, achter de troon die Nebukadnezar in Egypte (43:10) tot en met in Elam (49:38) opricht, rijst de troon van God op.

Een keerpunt brengt de profetie van Elam anderzijds, omdat hiermee de overgang naar de grote profetie tegen Babel in Jeremia 50-51 wordt voorbereid. Babel is Gods hamer $(50: 23 ; 51: 20)$ en Nebukadnessar Gods knecht $(25: 9 ; 27: 6 ; 43: 10)$, maar de werkelijke šar šarrāni is niet Nebukadnessar, maar de God van Israël, een Koning die zijn troon heeft opgericht in Elam, nabij Babel. Alle elementen van de oordeelsprofetie tegen Elam keren in de profetie tegen Babel terug: de verbreking van de boog (49:35-51:56); de vernietigende stormwind (49:36-51:1); de diaspora (49:36-50:2); de schrik voor de vijand (49:37-50:43; 51:30); het zwaard van God (49:37-50:35-38), en de uitroeiing van vorsten door dé Koning (49:38-51:57).

Binnen het geheel van de OAN-bundel in JerMT vervult de profetie tegen Elam een scharnierfunctie, waardoor enerzijds de bundel van zeven volkenprofetieën in 46:2-49:33 climactisch wordt afgesloten en anderzijds de profetie tegen Babel in 50-51 wordt voorbereid. Het spreken over "Gods troon in Elam" accentueert de intensiteit en onontkoombaarheid van het gericht over de volken, en werpt tegelijk een bijzonder licht op de aard en de grenzen van dit gericht. Op deze wijze heeft de Elam-profetie als literair-theologische brugtekst een passende plaats en functie in JerMT.

In JerLXX echter wordt deze profetie op de eerste positie gezet, op afstand van de Babel-profetie. Het is hier ook de enige profetie met een heilsbelofte (25:19). Nu zal de Elam-profetie niet at random de eerste plaats in de OAN-bundel hebben gekregen, omdat een dergelijke positionering een tekst ook een extra accent geeft. Een al oude interpretatie is dat JerLXX met de naam Elam in feite Perzië beoogt, hetgeen de prioritering van de Elamprofetie zou kunnen verklaren (zie onder). Het is echter niet waarschijnlijk dat de oorspronkelijke OAN-bundel deze bijzondere interesse voor Perzië als eerste in de rij die het gericht van JHWH moet ondergaan, reeds gehad zou hebben - het sentiment richting Perzië zal lange tijd na de Babylonische ballingschap positief zijn geweest (om welke reden het Oude Testament dan ook geen profetie tegen Perzië bevat). Bovendien vertoont de plaatsing van de Elam-profetie in JerLXX secundaire redactionele bewerking (zie boven): het hybride opschrift in 25:14 en de afwijkende plaatsing van de historische notitie als onderschrift in 26:1. 
Dit alles lijkt erop te wijzen dat de profetie tegen Elam oorspronkelijk niet op de eerste positie in de OAN-bundel heeft gestaan zoals in JerLXX, maar door latere bewerking daar een plaats heeft gekregen. Zo passend als de Elam-profetie - literair, structureel en theologisch gezien - een plaats in JerMT heeft, zo onbegrijpelijk is haar plaats in (de Vorlage) van JerLXX. Dit gegeven pleit niet voor de prioriteit van de volgorde van de volkenprofetieën in JerLXX.

\section{KANTTEKENING (4): DE PLAATS VAN DE PROFETIE TEGEN BABEL}

De laatste maar niet de minst belangrijke kanttekening bij de groeiende consensus betreft de plaats van de grote Babel-profetie in hoofdstukken 27-28 JerLXX. Een eerste observatie is dat door deze positionering de profetie tegen Egypte (26) en die tegen Filistea (29) van elkaar worden gescheiden. Dit zijn twee landen die geografisch en historisch nauw verbonden zijn. Stilistisch en retorisch hebben deze beide profetieën veel gemeen. Wat thematiek, beeldtaal en idioom betreft, zijn er allerlei overeenkomsten (de aanzwellende wateren; de bevolking die in paniek niet omkeert; de vijand uit het noorden; de komende gerichtsdag, en het zwaard; zie Peels 2017). Een directe aansluiting zoals in JerMT (hoofdstukken 46 en 47) ligt dan ook meer voor de hand dan de gescheiden positie in JerLXX.

Zwaarwegender nog is het punt dat de Babel-profetie in JerLXX een plaats heeft gekregen in het midden van de OAN-bundel, tussen de andere volkenprofetieën in. Niet alleen qua omvang, maar ook wat de inhoud betreft, verschilt de Babel-profetie echter aanzienlijk van de andere volkenprofetieën. Structuur en opzet van de profetie, die weinig specifieke voortgang vertoont, tenderen naar een maximale accentuering van deze ene vijandige natie, Babel, die de ondergang van Juda, Jeruzalem en de tempel van JHWH heeft bewerkstelligd. Babel wordt ennemi par excellence, waarvan de contouren tijd en plaats transcenderen: chiffre van de opperste kwaadaardigheid tegen JHWH. Waar in de OAN-bundel Babel de grote bedreiging vormt als de vleesgeworden "vijand uit het Noorden", wordt in 50-51 [27-28] Babel zelf het slachtoffer, nu van een nieuwe "vijand uit het Noorden": de Meden. Alleen in déze volkenprofetie is expliciet sprake van het geweld dat Israël is aangedaan, en alleen hier wordt geprofeteerd over de verlossing van Israël en de terugkeer van de ballingen. In alle geuren en kleuren wordt de ondergang van deze aartsvijand van Israël en van Israëls God geschilderd. De profetie bevat een groot aantal citaten van eerdere passages uit het Boek van Jeremia, en teksten uit andere profetenboeken. 
Tussen geleerden is weinig verschil van mening over het feit dat de Babelprofetie een tekst is die in alle opzichten de indruk maakt een samengesteld geheel te vormen en vergeleken met de andere volkenprofetieën later gedateerd dient te worden, en daar dus oorspronkelijk los van stond (Haran 2003:700-701; Reimer 1993:260; Sals 2004:400-402).

Wanneer de grote Babel-profetie, die qua omvang, structuur en theologie afwijkt van de andere OAN, uit later tijd stamt, mag verwacht worden dat deze bij toevoeging aan de bundel volkenprofetieën een plaats ontvangt aansluitend bij en na de andere profetieën, maar niet ergens in het midden daarvan. Ook deze observatie pleit tegen de prioriteit van de volgorde van de OAN-bundel in JerLXX.

\section{CONCLUSIE EN HYPOTHESE}

Uit het voorgaande kunnen wij concluderen dat de gemaakte "kanttekeningen", ofschoon zij niet alle dezelfde kracht van argumentatie hebben, tezamen toch voldoende gewicht in de weegschaal leggen om de groeiende consensus inzake de originaliteit van de volgorde van de OAN in JerLXX kritisch te bezien. Er is tekstevidentie om de optie dat de volgorde in JerMT oorspronkelijker is, open te houden. Temeer, daar deze laatste zoals eerder geconstateerd beter past in de totaalboodschap van het Boek van Jeremia, met zijn dynamische ontwikkeling van de motieven van Egypte (object valse hoop) en Babel (strafinstrument van JHWH), die ten slotte beide onder het oordeel van God komen.

Elk voorstel ter verklaring van de verschillen tussen de MT- en LXXvolgorde "is based upon pure conjecture", aldus Haran (2003:700), die zelf met excuus afziet van een poging tot nadere uitleg. Zo makkelijk zal het volgens Stipp (2014:500) echter niet kunnen gaan: wie een latere redactionele ingreep veronderstelt, moet hiervoor ook een goede reden aanvoeren. Een poging in deze richting is mogelijk, maar zal niet verder komen dan het niveau van een bescheiden voorstel.

Het is mijn hypothese dat de volgorde van de volkenprofetieën zoals die in de oorspronkelijke OAN-bundel voorlag met Egypte als eerste en Babel als laatste, in de loop van de vierde of derde eeuw BCE bewust veranderd is om deze bundel voor de lezer/hoorder een actualisering te geven met het oog op de nieuwe tijdsomstandigheden. De politieke constellatie van Jeremia's dagen, met de "balance of power" tussen Egypte en Babel, is in later eeuwen heel anders. Niet langer speelt Babel de hoofdrol in de geschiedenis. Perzië is de grootmacht die sinds de val van Babel in 539 BCE de wereld heeft beheerst. Terecht hebben exegeten verondersteld dat de 
naam Elam in JerLXX voor Perzië staat (Rudolph 1968:266; Weiser 1981:389; McKane 1986:645; Schmidt 2013:281; Finsterbusch \& Jacoby 2015:41). In historisch perspectief zijn deze twee immers één. In het bekervisioen in JerLXX worden de koningen van Elam en die van Perzië (niet zoals in JerMT: Medië) in een adem genoemd (32:25; zo ook in JesLXX 21:3, zie 49:12). In de zesde eeuw BCE hadden de Perzische heersers de oude Elamitische titel "koning van Anšan" overgenomen, en zich daarmee als legitieme opvolgers van de Elamitische koningen gepresenteerd. Het Elamitisch was een van de officiële talen van het Perzische wereldrijk. Ruim twee eeuwen was voor de volken van het oude Nabije Oosten, inclusief Egypte, de Perzische heerschappij dominant. In een rij met volken die in profetisch perspectief onder JHWH's oordeel vallen, kan dan Perzië niet ergens tussen andere een ondergeschikte plaats innemen.

Finsterbusch \& Jacoby veronderstellen dat de vooropstelling van de Elam-profetie reeds in de Jer-Vorlage in de Perzische tijd een gegeven was, en dat daarbij een zekere "diplomatie" een rol heeft gespeeld. De Elamprofetie is in JerLXX immers de enige met een afsluitend heilswoord (25:19:

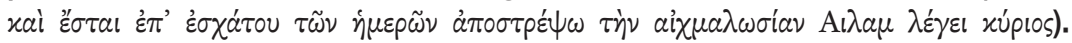
JHWH zal Perzië niet aan de ondergang prijsgeven, anders dan Babel, zo is de impliciete boodschap van deze ordening (zie Finsterbusch \& Jacoby 2015:44). Ondertussen valt in de rij der volken Elam/Perzië terdege onder het goddelijk oordeel, en wel als eerste, in JerLXX - en hoe diplomatiek is dat.

Daarom is het wellicht beter om te denken aan een latere fase van de tekstontwikkeling, in de tijd van de ondergang van het Perzische wereldrijk in de tweede helft van de vierde eeuw BCE of daarna, dat de redactor met een doelbewuste ingreep de volgorde van de OAN-bundel heeft veranderd. Hij positioneerde Elam/Perzië als eerste: dit was het grootste rijk van alle, omvatte alle volken van het oude Nabije Oosten, is ook als laatste van alle ten onder gegaan. Deze volgorde is aangehouden door de Griekse vertaler, levend in het Ptolemeïsche Egypte dat in zekere zin ook erfgenaam van het Perzische rijk was, en waar de herinnering aan de neergang van het Perzische rijk nog vers in het geheugen lag. Hiermee onderstreepte hij de actualiteit van de OAN voor zijn Hellenistisch-Egyptische tijdgenoten. De God van Israël heeft een geding met de gehele wereld - de grote rijken moeten voor Hem buigen, ook het allergrootste: Elam/Perzië.

De Elam-profetie krijgt hiermee een paradigmatische functie: onder het oordeel van JHWH gekomen, maar niet zonder hoop. Wat Elam overkomt, heeft betekenis voor het handelen Gods aan alle volken van de wereld van toen. Mogelijk kan zelfs verondersteld worden dat JerLXX het hybride

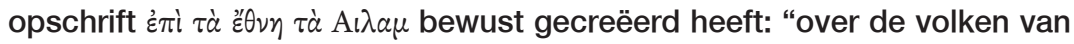


Elam". Immers, alle volken die in de OAN-bundel genoemd worden, waren eeuwenlang voor langere of kortere tijd deel van dit "Elam". Waar voorheen in de OAN-bundel Babel het hoofdaccent innam, heeft in het Ptolemeïsche Egypte, in een tijd waarin kennis van Babylonië en de historische finesses van het gebeuren in de zesde eeuw BCE allang overvleugeld was door het wel en wee van het Perzische wereldrijk, JerLXX de essentie van het goddelijk wereldgericht voor de eigen tijdgenoten willen accentueren in deze nieuwe ordening van de volkenprofetieën, de grote rijken voorop, met Elam als eerste en Elam bij uitstek.

\section{BIBLIOGRAPHY}

\section{Aejmeleaus, $A$.}

2002. Jeremiah at the turning-point of history. The function of Jer. XXV 1-14 in the book of Jeremiah. VT 52:459-482.

Allen, L.C.

2008. Jeremiah. A commentary. Louisville, KY: Westminster John Knox. OTL.

Backhaus, F.-J. \& MeYer, I.

2012. Das Buch Jeremia. In: E. Zenger (Hg.), Einleitung in das Alte Testament (Stuttgart: Kohlhammer, Studienbücher Theologie 1,1), pp. 548-577.

Brueggemann, W.

1998. A commentary on Jeremiah. Exile and homecoming. Grand Rapids, MI: W.B. Eerdmans.

Carroll, R.P.

1986. Jeremiah. A commentary. London: SCM. OTL.

Chae, M.K.

2015. Redactional intentions of MT Jeremiah concerning the oracles against the nations. Journal of Biblical Literature 134:577-593.

Cоoк, J.

1994. The difference in the order of the books of the Hebrew and Greek versions of Jeremiah - Jeremiah 43 (50): A case study. Old Testament Essays 7:175-192.

Crouch, C.L.

2017. An introduction to the study of Jeremiah. London: Bloomsbury.

FinsteRBUSCH, K. \& JACOBY, N.

2015. Völkergericht und Fremdvölkersprüche. Kommunikationsebenen in (der hebr. Vorlage von) LXX-Jer 25-32, MT-Jer 46-51 und MT-Jer 25. Journal of Ancient Judaism 6:36-57.

FISCHER, G.

1991. Jer 25 und die Fremdvölkersprüche: Unterschiede zwischen hebräischem und griechischem Text. Biblica 72:474-499. 
2017. Septuagint. In: A. Lange \& E. Tov (eds), Textual history of the Bible. The Hebrew Bible. Volume 1B: Pentateuch, former and latter prophets (Leiden: Brill), pp. 543-555.

FOHRER, G.

1981. Vollmacht über Völker und Königreiche (Jer 46-51). In: G. Fohrer, Studien zu alttestamentlichenTexten und Themen (1966-1972) (Berlin: De Gruyter, BZAW 155), pp. 44-52.

\section{GESUNDHEIT}

2012. The question of LXX Jeremiah as a tool for literary-critical analysis. $V T$ 62:29-57.

Gosse, B.

1986. La malédiction contre Babylone de Jérémie 51,59-64 et les rédactions du livre de Jérémie. Zeitschrift für die Alttestamentliche Wissenschaft 98:383-399.

1990. Jeremie xlv et la place du recueil d'oracles contre les nations dans le livre de Jeremie. Vetus Testamentum 40:145-151.

1994. La place primitive du recueil d'oracles contre les nations dans le livre de Jérémie. Biblische Notizen 74:28-30.

HaRAN, M.

2003. The place of the prophecies against the nations in the Book of Jeremiah. In: S.M. Paul \& E. Ben-David (eds), Emanuel: Studies in Hebrew Bible, Septuagint, and Dead Sea scrolls (Fs E. Tov) (Leiden: Brill), pp. 699-703.

HolladaY, W.L.

1986. Jeremiah 1. A commentary on the book of the prophet Jeremiah Chapters 1-25. Minneapolis, MN: Fortress Press. Hermeneia.

1989. Jeremiah 2. A commentary on the book of the prophet Jeremiah Chapters 26-52. Minneapolis, MN: Fortress Press. Hermeneia.

HuWYLER, B.

1997. Jeremia und die Völker. Untersuchungen zu den Völkersprüchen in Jeremia 46-49. Tübingen: Mohr Siebeck. FAT 20.

JANZEN, J.G.

1973. Studies in the text of Jeremiah. Cambridge, MA: Harvard University Press. HSM 6.

Kessler, M.

2003. Battle of the Gods. The God of Israel versus Marduk of Babylon. A literary/ theological interpretation of Jeremiah 50-51. Assen: Van Gorcum. SSN 42.

2004. The scaffolding of the Book of Jeremiah. In: M. Kessler (ed.), Reading the book of Jeremiah. A search for coherence (Winona Lake, IN: Eisenbrauns), pp. 57-66. 
LANGE, A.

2017. Ancient Aramaic and Hebrew texts. In: A. Lange \& E. Tov (eds), Textual history of the Bible. The Hebrew Bible. Volume 1B: Pentateuch, former and latter prophets (Leiden: Brill), pp. 514-542.

LUNDBOM, J.R.

2004. Jeremiah 37-52. A new translation with introduction and commentary. New York: Doubleday. AB.

MAIER, M.P.

2002. Ägypten - Israels Herkunft und Geschick. Studie über einen theopolitischen Zentralbegriff im hebräischen Jeremiabuch. Frankfurt am Main: Peter Lang. Österreichische Biblische Studien 21.

McKane, W.

1986. A critical and exegetical commentary on Jeremia. Vol. 1, Jeremiah I-XXV. Edinburgh: T. \& T. Clark. ICC.

1996. A critical and exegetical commentary on Jeremia. Vol. 2, Jeremiah XXVILII. Edinburgh: T. \& T. Clark. ICC.

Peels, H.G.L.

2000. God's throne in Elam. The historical background and literary context of Jeremiah 49:34-39. In: J.C. de Moor \& H.F. van Rooij (eds), Past, present, future. The deuteronomistic history and the prophets (Leiden: Brill, OTS 44), pp. 216-229.

2007. "You shall certainly drink!" The place and significance of the oracles against the nations in the book of Jeremiah. European Journal of Theology 16:81-92.

2013. Before pharaoh seized Gaza. A reappraisal of the date, function, and purpose of the superscription of Jeremiah 47. Vetus Testamentum 63:308-322.

2016. Een slachtoffer heeft JHWH in het Noorderland (Jer. 46:10). In die Skriflig 50(3). a1999. [Aanlyn.] Bekomt van: http://dx.doi.org/10.4102/ids.v50i3.1999 [jaar, datum en maand

2017. "Gaza is kaal geschoren". Tekst en intentie van de gerichtsprofetie over Filistea (Jer. 47). In: A. Huijgen, H.G.L. Peels \& C.-J. Smits (reds), Schuld en vrijheid. Opstellen aangeboden aan prof. dr. G.C. den Hertog (Zoetermeer: Boekencentrum), pp. 225-238.

2018. "But Fear not, O Jacob my Servant!" The place and function of the salvation oracle Jeremiah 46:27-28 MT. In: K. van Bekkum, G. Kwakkel \& W.H. Rose (eds.), Biblical Hebrew in context. Essays in Semitics and Old Testament Texts in Honour of Professor Jan P. Lettinga, (Leiden: Koninjklike Brill), pp. 114-129.

Peels, H.G.L. \& Snyman, S.D.

2012. The lion has roared. Theological themes in the prophetic literature of the Old Testament. Eugene, OR: Wipf \& Stock. 


\section{Pfeiffer, R.H.}

1948. Introduction to the Old Testament. New York: Harper \& Bros.

REIMER, D.J.

1993. The oracles against Babylon in Jeremiah 50-51. A horror among the nations. San Francisco, CA: University Press.

Rofé, A.

1989. The arrangement of the book of Jeremiah. Zeitschrift für die Alttestamentliche Wissenschaft 101:390-398.

RUDOLPH, W.

1968. Jeremia. Tübingen: Mohr Siebeck. HAT.

SALS, U.

2004. Die Biographie der "Hure Babylon“. Studien zur Intertextualität der Babylon-Texte in der Bibel. Tübingen: Mohr Siebeck. FAT II/6.

SCHMIDT, W.H.

2013. Das Buch Jeremia. Kapitel 21-52. Göttingen: Vandenhoeck\&Ruprecht. ATD.

SNYMAN, S.D.

2015. Historical commentary on the Old Testament. Leuven: Peeters.

STIPP, H.-J.

1994. Das masoretische und alexandrinische Sondergut des Jeremiabuches. Textgeschichtlicher Rang, Eigenarten, Triebkräfte. Göttingen: Vandenhoeck\&Ruprecht. ОВО 136.

2014. Legenden der Jeremia-Exegese (I): Das eschatologische Schema im alexandrinischen Jeremiabuch. VT 64:484-501.

Volz, P.

1922. Der Prophet Jeremia. Leipzig: Scholl. KAT 10/2.

WATTS, J.W.

1992. Text and redaction in Jeremiah's oracles against the nations. Catholic Biblical Quarterly 54:432-447.

WEIS, R.D.

2017. Textual history of Jeremiah. In: A. Lange \& E. Tov (eds), Textual history of the Bible. The Hebrew Bible. Volume 1B: Pentateuch, former and latter prophets (Leiden: Brill), pp. 495-513.

WEISER, A.

1977. Das Buch Jeremia. Göttingen: Vandenhoeck\&Ruprecht. ATD 20/21.

Woods, J.

2011. Jeremiah 48 as Christian scripture. Eugene, OR: Wipf\&Stock. Princeton Theological Monograph Series 149. 
Peels De volgorde van de volkenprofetieën in het boek Jeremia

Keywords

Old Testament

Oracles Against the Nations

Elam prophecy

JerMT and JerLXX

Redaction history of the Book of Jeremiah
Trefwoorde

Ou Testament

Orakels teen die nasies

Profesie teen Elam

JerMT en JerLXX

Redaksiegeskiedenis van die Boek van Jeremia 